\title{
Proactivity and Employee Creativity: Mediator Roles of Feedback-Seeking Behavior and Moderating Effect of Task Feedback
}

\section{Fajrin Putra Utama ${ }^{\mathrm{a}}$ and Debora Eflina Purba ${ }^{\mathrm{b}}$}

${ }^{a}$ Faculty of Psychology, Universitas Indonesia, Depok, Indonesia; ${ }^{b}$ Department of Industrial and Organizational Psychology, Faculty of Psychology, Universitas Indonesia, Depok, Indonesia

*Corresponding author:

Debora Eflina Purba

Department of Industrial and Organizational Psychology,

Faculty of Psychology, Universitas Indonesia

Depok, Jawa Barat, Indonesia

Tel.: +62 217270004

Email: eflina@ui.ac.id 


\title{
Proactivity and Employee Creativity: Mediator Roles of Feedback-Seeking Behavior and Moderating Effect of Task Feedback
}

\begin{abstract}
Employee creativity is needed in this ever-changing environment, especially in profit-making companies. To stand out among competitors, proactivity and creativity are essential for marketing employees to attain top performance. The literature has found inconsistent results regarding the relationship between proactivity and creativity. Research has shown that the interaction between individual and environmental factors determines employee behavior. Thus, we focus on the interaction between an individual factor such as proactivity and an environmental factor such as task feedback to predict creativity. In this study, we use a sample of 256 marketing employees from seven companies in Indonesia. The results indicate that feedback-seeking behavior mediates the relationship between proactive personality and employee creativity. Task feedback moderates the relationship between a proactive personality and feedback-seeking behavior such that the relationship becomes stronger when the task feedback is positive than when the feedback is negative. Theoretical and practical implications of this study's contribution to literature are discussed.
\end{abstract}

Keywords: employee creativity, feedback-seeking behavior, marketing employee, proactivity, task feedback

\section{Introduction}

Creativity, defined as the employee's ability to produce or generate a useful new idea, is a critical behavior in an organization, especially for marketing employees, mainly because they need to adapt to the ever-changing needs in the market (Amabile, 1988; Borden, 1984). Creativity has a positive impact on individual and organizational outcomes, for example, increased job performance for sales employees, innovation capability of the firm, and organizational competitiveness (Gong, Huang, \& Farh, 2009; Hassan, Malik, Hasnain, Faiz, \& Abbas, 2013; Oldham \& Cumming, 1996). The literature has found many factors of employee creativity, and the factors can be divided into two categories: individual and contextual factors. Individual factors comprise the cognitive-related characteristics such as capability for divergent thinking (Jain \& Jain, 2017), intrinsic motivation (Chang \& Teng,2017), personality dispositions, for example, openness to experience and conscientiousness (George \& Zhou, 2001), and proactivity (Gong, Cheung, Wang, \& Huang, 2012). Contextual factors comprise socio-environmental variables (trusting work environment, good relationship with co-worker, time), job-characteristic-related variables (feedback, autonomy, job complexity and reward), and leadership styles (supportive and controlling supervisor style) (Oldham \& Cumming, 1996; Seibert, Crant, and Kraimer, 1999; Shalley, Zhou, Oldham, 2004).

This study focuses on one of the individual factors, namely, proactivity. Proactivity is defined as the predisposition of an individual to take initiative, anticipate future problems, and seize every opportunity (Bateman \& Crant, 1993; Bateman \& Crant, 1999; Crant, 2000). To generate a greater number of and useful ideas for the company, an employee must take initiative in 
gathering any useful information to improve their performance. Studies have been conducted on the relationship between proactivity and creativity (Gong et al., 2012; Kim \& Wang, 2008; Kim, Hon, \& Crant, 2009). Most of the studies have found a positive correlation between proactivity and creativity, but the range of coefficients are small $(\leq 0.25)$ (Costa, Paez, Sanchez, Garaigordobil, \& Gondim, 2015). A review paper on the proactivity-creativity relationship encouraged researchers to conduct more research on its underlying processes (Jain \& Jain, 2017).

In this study, we focus on feedback-seeking behavior as the underlying mechanism between proactivity and creativity relationship. We use conservation of resources (COR) theory (Hobfoll, 1989) to explain our mediation model. COR theory explains how people acquire, use, and maintain their resources to survive threats from the environment and avoid stress (Hobfoll, 1989). Because the company must follow the change in the market, the employee could be in distress from following the demand to be more proactive and creative. Seeking advice from supervisors could become one of the coping strategies for employees (Ito \& Brotheridge, 2003). Based on COR theory, proactivity is as an individual resource that enables individuals to take initiatives and seek opportunities, including feedback-seeking behaviors, which increases their creativity. However, we argue that the mediation effect of feedback-seeking behavior is dependent on the task feedback (positive or negative) an individual receives from their supervisors.

We use job characteristic model theory (JCM) (Hackman \& Oldham, 1976) to explain the moderating role of task feedback. JCM theory explains that there are characteristics of the tasks that can influence the intrinsic motivation of the employee. One of the characteristics is feedback (Hackman \& Oldham, 1976). As the characteristic of the job can influence the employee motivation, by using JCM, we provide context for the inconsistent relationship between proactivity and feedback-seeking behavior (Kim \& Wang, 2008; Wu, Parker, De Jong, 2014). Based on JCM theory, we assumed that task feedback (i.e., positive or negative) would influence the relationship between proactivity and feedback-seeking behavior because the valence of the feedback may encourage or discourage their behavior in gathering information about their job from their supervisor.

This study makes several contributions to the literature. First, we integrate individual and contextual factors of creativity by offering feedback-related variables as important psychological mechanisms relating to proactivity and creativity. Second, we collect the data by combining two types of reports: supervisor reports and self-reports. Third, we use the COR and JCM theories to explain our model. The research on proactivity and creativity have used other theories to explain the relationship, namely, psychological safety, person-environment fit, and trait-activation theory (Gong et al., 2012; Jiang \& Gu, 2015; Kim, Hon, \& Lee, 2010).

\section{Theories and Hypotheses}

\section{Mediating relationship between proactivity and employee creativity}

Research has shown a positive relationship between proactivity and creativity (Gong et al., 2012; Jain \& Jain, 2017; Jiang \& Gu, 2015; Kim \& Wang, 2008; Kim et al., 2009). Proactive 
people actively make constructive changes in their environment, are willing to take a risk to generate new ideas, and reduce risk by gathering the information to anticipate future change and enhance their performance level (Oldham \& Cummings, 1996; Jain \& Jain, 2017; Gong et al., 2012). However, research has also shown that the relationship between proactivity and creativity tends to be indirect. Costa, Paez, Sanchez, Garaigordobil, and Gondim, in their meta-analysis, found that the correlation coefficient between proactivity and creativity was small $(r=0.25)$ [17]. Additionally, Gong et al. (2012) found that information exchange and trust in a supervisor mediated the relationship between proactivity and creativity; other research has found that job requirement and supervisory support jointly influenced the relationship (Kim et al. , 2010); and other research has used felt responsibility to change as a variable to explain the relationship between proactivity and creativity (Jiang \& Gu, 2015).

In this study, we argue that feedback-seeking behavior mediates the relationship between proactivity and creativity. According to Anseel, Beatty, Shen, Lievens, and Sackett (2015), proactive people employ feedback-seeking behavior to decrease the environmental uncertainty, to achieve their goal, and to enhance their performance. According to Li and Qian (2016), feedback-seeking behavior is an individual effort that comprises an employee asking other people such as supervisors and colleagues to provide their opinions about the employee's behavior and performance at work. Based on COR theory, proactivity is a critical individual resource, especially for marketing employees, who are required to take initiative and plan their work. To improve their functioning at work, proactive people use their personal resources to have the courage to seek feedback from their supervisor regarding their tasks. Feedback is an important factor that enables proactive people to improve their performance and influence results. Feedback can also develop trust between the supervisor and the employee by creating the feeling of a supportive work environment. As a result, employees who ask for feedback are considered creative employees by their supervisors (Baker, Perreault, Reid, \& Blanchard, 2013; Ilgen, Fisher, \& Taylor, 1979). Thus, we propose Hypothesis 1:

Hypothesis 1: The relationship between proactivity and creativity is mediated by feedbackseeking behavior.

\section{Moderationg role of task feedback}

De Stobbelier, Ashford, and Buyens asserted that feedback-seeking behavior is a strategy used by proactive employees to conduct self-regulation and to enhance their performance (De Stobbeleir, Ashford, \& Buyens, 2011). Kim and Wang (2008) found a positive relationship between proactivity and feedback-seeking behavior. However, Wu, Parker, and De Jong (2014) found no significant relationship between proactivity and feedback-seeking behavior. The inconsistency of the results found by these researchers indicates a moderating variable on the relationship between proactivity and feedback-seeking behavior.

Based on JCM (Hackman \& Oldham, 1976) as a framework, we argue that whether a proactive employee will engage in feedback-seeking behavior is dependent on the task feedback (i.e., positive or negative) they receive from others. Hon, Chan, and Lu (2013) defined task feedback as the type of feedback oriented to tasks, namely, positive task feedback and negative task 
feedback (Hon et al., 2013). Positive task feedback is feedback that can reinforce employees because it comprises compliments and support from the supervisor (Anseel et al., 2015). Negative task feedback is less acceptable feedback that tends to decrease employee's performance and comprises criticism, cynicism, or any form of feedback that devalues an individual's work and is used as a form of punishment (Baker et al., 2013). Proactive employees engage in feedback-seeking behavior when they perceive that their supervisor provides positive feedback rather than negative feedback. Thus, we propose Hypothesis 2:

Hypothesis 2: The positive relationship between proactivity and feedback-seeking behavior is moderated by task feedback such that the relationship is stronger for positive compared with negative task feedback.

In addition, we propose that the task feedback moderates the indirect effect of proactive personality on employee creativity through feedback-seeking behavior. Proactive employees that receive positive task feedback show higher level of feedback-seeking behavior to obtain more information from supervisors to help them be creative. However, when proactive employees receive negative task feedback, they tend to avoid feedback-seeking behaviors, which would lower their creativity (Anseel et al., 2015; De Stobbeleir et al., 2011; Kim \& Wang, 2008; Zhou, 1998). Therefore, we propose Hypothesis 3:

Hypothesis 3: The indirect effect of proactive personality on employee creativity through feedback-seeking behavior is conditional on task feedback such that this indirect relationship is more significant when the positive task feedback received than when the negative task feedback received.

\section{Methods}

\section{Sample and Procedure}

Data was taken from seven companies in various industries, such as bank, distributorship, retail, dealership, outsourcing services, and manufacturing, in Indonesia. Data were collected using the survey method. Before conducting the survey, we sent a research proposal to the companies. After permission was granted by the company, we approached the marketing division and asked supervisors and their employees to participate in the survey.

There were two types of questionnaires administered, supervisors rated their employees on the creativity variable, and employees self-reported their proactivity, feedback-seeking behavior, and task feedback variables. To observe relationships between the two surveys, we developed codes to avoid asking for personal information. We informed the participants that the survey was confidential and voluntary and they could terminate their participation anytime.

We distributed 500 questionnaires to the companies and collected 317 questionnaires from employees and 29 supervisors (response rate $=63,4 \%$ ). From the 317 questionnaires, we excluded 61 because of incomplete information and extreme responses; thus, 256 questionnaires were used for the analysis. Of the 256 questionnaires, $70.3 \%$ were from male employees. 
Regarding educational level, $27.7 \%$ finished high school, $6.3 \%$ had earned a diploma III, $64.1 \%$ had earned a bachelor's degree, $2 \%$ had earned postgraduate degrees. Regarding age, $55.5 \%$ were aged younger than 30 years, and the average tenure was 3.30 years $(\mathrm{SD}=3.22)$. Next, we analyzed the data by using a moderated mediation model on Hayes' PROCESS macro on SPSS software.

\section{Measurements}

All measures were in English, and we translated the measures into the Indonesian language using the translate-back translate procedure.

\section{Proactivity}

Proactivity was measured using a 10-item scale developed by Seibert et al. (1999). A sample item is as follows, "I am always looking for better ways to do things." The response scale ranged from 1 (strongly disagree) to 7 (strongly agree). This measurement is valid and reliable because the Cronbach's alpha of this measurement was 0.887 .

\section{Feedback-seeking Behavior}

Feedback-seeking behavior was measured with a 4-item scale adapted from Fedor, Rensvold, and Adam (1992). A sample item is as follows, "I talk to my supervisor about my performance" The response scale ranged from 1 (strongly disagree) to 5 (strongly agree). The Cronbach's alpha of this measurement was 0.878 .

\section{Taskfeedback}

Task feedback was measured with a 7-item scale adapted from George and Zhou [8]. Participants responded to items, such as "My supervisor often criticizes my work." The response scale ranged from 1 (strongly disagree) to 7 (strongly agree). The Cronbach's alpha of positive feedback was. 886 and for negative feedback was 0.862 .

\section{Creativity}

Creativity was measured with four items adapted from Tierney, Farmer, and Graen (1999). An example item is as follows, "this employee is a good role model for creativity." The response scale ranged from 1 (strongly disagree) to 6 (strongly agree). The Cronbach's alpha of this measurement was 0.848 .

\section{Control Variables}

In all the analysis, we entered the following control variables: age, sex, tenure, and education level. These control variables were included in the analysis because researchers have included them because of their possible association with creativity (Gong et al., 2012). Older employees tend to become less creative (Jain \& Jain, 2017). Women were found to be more creative than men. Moreover, educational level was positively related to creativity (Amabile, 1988). Lastly, the longer the tenure in the organization, the less creative employees become (Jiang \& Gu, 2015). 


\section{Results}

\section{Confirmatory Factor Analysis}

Before testing the hypotheses, we performed CFA to test the discriminant validity of our study variables. Based $\mathrm{Hu}$ and Bentler, we seek the close cut-off value of $\chi 2$, df, RMSEA, SRMR, and CFI to obtain the relatively good fit of the model that we proposed [34]. Table 1 presents the model comparison of our model and other alternative models. Table 1 presents a 5-factor solution that demonstrates relatively good fit compared with the other alternative models. Therefore, we used the 5-factor solution for further analyses.

\section{Descriptive Statistic}

Means, standard deviations, and correlations are variables presented in Table 2. In Table 2, we observed a positive and significant correlation between proactivity and feedback-seeking behavior ( $\mathrm{r}=0.182, \mathrm{p}<.01$ ), and a negative and significant correlation between feedbackseeking behavior and creativity $(r=-0.125, \mathrm{p}<.05)$.

\section{Hypothesis Testing}

Figure 1 presents our research model and the path coefficients between variables. Feedbackseeking behavior mediates the relationship between proactive personality and employee creativity. In Figure 1, we observed that the relationship between proactivity and feedbackseeking behavior is significant $(\beta=0.1957, \mathrm{p}<0.01, \mathrm{SE}=0.0639,95 \% \mathrm{CI}[0.0698,0.3216])$ and the relationship between feedback-seeking behavior and creativity is significant $(\beta=$ $0.1599, \mathrm{p}<0.05, \mathrm{SE}=0.0670,95 \%$ CI $[-0.2917,-0.0280])$. Hypothesis 1 posited that feedbackseeking behavior mediated the relationship between proactivity and creativity.

Table I. Confirmatory Factor Analysis

\begin{tabular}{llcccc}
\hline \multirow{2}{*}{ Model } & \multicolumn{5}{c}{ Criteria for good fit indexes } \\
\cline { 2 - 6 } & $\chi^{2}$ & $\boldsymbol{d f}$ & $\boldsymbol{R M S E A}$ & $\boldsymbol{S R M R}$ & $\boldsymbol{C F I}$ \\
\hline $\begin{array}{l}\text { 1 Factor (All variables become } \\
\text { one single factor) }\end{array}$ & 2301.94 & 275 & 0.170 & 0.14 & 0.64 \\
$\begin{array}{l}\text { 4 Factors (Proactivity, FSB, } \\
\text { Creativity, and Task feedback) }\end{array}$ & 917.70 & 246 & 0.103 & 0.099 & 0.83 \\
$\begin{array}{l}5 \text { Factors (Same as model 4, but } \\
\text { task feedback is divided into } \\
\text { positive task feedback and } \\
\text { negative task feedback) }\end{array}$ & & & & & \\
\hline
\end{tabular}


Table II. Descriptive Statistics

\begin{tabular}{|c|c|c|c|c|c|c|c|c|c|c|c|}
\hline \multirow{2}{*}{ Variable } & \multicolumn{11}{|c|}{ Mean, SD, and Correlation } \\
\hline & Mean & $S D$ & 1 & 2 & 3 & 4 & 5 & 6 & 7 & 8 & 9 \\
\hline Gender & 1.30 & 0.46 & 1 & & & & & & & & \\
\hline Age & 29.9 & 5.61 & $-0.213 * *$ & 1 & & & & & & & \\
\hline Education & 2.40 & 0.92 & 0.107 & $0.172 * *$ & 1 & & & & & & \\
\hline Tenure & 3.30 & 3.22 & -0.061 & $0.671^{* *}$ & 0.100 & 1 & & & & & \\
\hline Proactivity & 5.77 & 0.61 & -0.073 & $0.203^{* *}$ & -0.041 & $0.151^{*}$ & 1 & & & & \\
\hline $\begin{array}{l}\text { Feedback-Seeking } \\
\text { Behavior }\end{array}$ & 3.74 & 0.73 & $-0.157^{*}$ & $0.216^{* *}$ & $0.125^{*}$ & $0.182 * *$ & $0.373^{* *}$ & 1 & & & \\
\hline Creativity & 4.40 & 0.78 & 0.049 & -0.098 & -0.042 & -0.090 & 0.034 & $-0.125^{*}$ & 1 & & \\
\hline $\begin{array}{l}\text { Task Feedback } \\
\text { Positives }\end{array}$ & 5.57 & 0.86 & -0.051 & $0.195^{* *}$ & -0.031 & 0.108 & $0.520^{* *}$ & $0.449 * *$ & -0.068 & 1 & \\
\hline $\begin{array}{l}\text { Task feedback } \\
\text { Negatives }\end{array}$ & 3.52 & 1.55 & 0.005 & 0.023 & 0.084 & 0.100 & -0.050 & $0.136^{*}$ & $-0.172 * *$ & 0.053 & 1 \\
\hline
\end{tabular}

Notes: $\mathrm{N}=256,{ }^{*} \mathrm{p}<0.05 * * \mathrm{p}<0.01$ (two-tailed)

Our results in Figure 1 showed that feedback-seeking behavior mediated the relationship between proactivity and creativity, as the indirect effect of proactivity on creativity is through feedback-seeking behavior is significant (indirect effect $=-0.0596 \mathrm{SE}=0.0282,95 \%$ CI [0.1197, -0.0095]). Therefore, our data support Hypothesis 1.

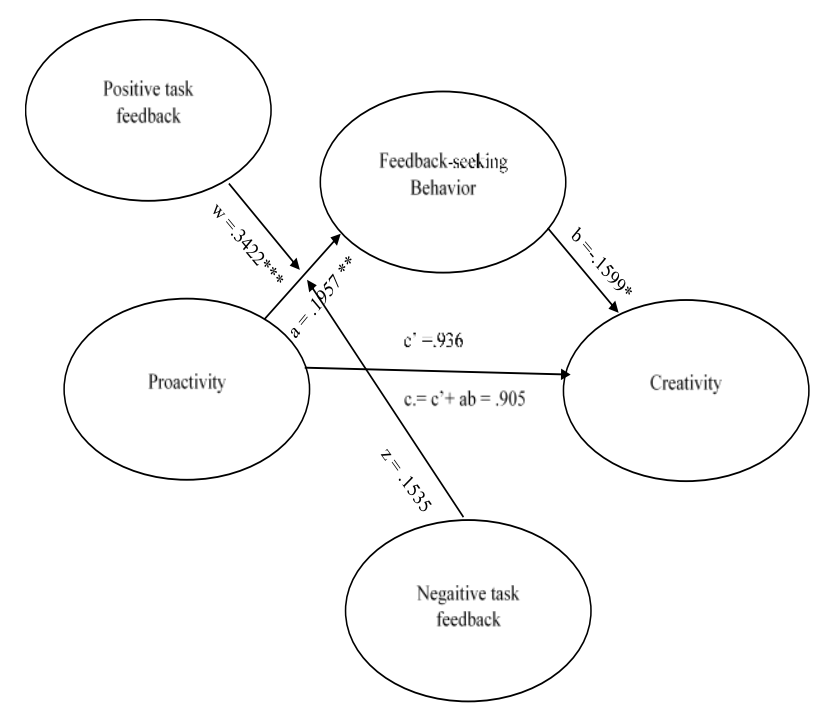

Fig. 1. Research Model and Beta Coefficient

Hypothesis 2 posited that task feedback moderated the relationship between proactivity and feedback-seeking behavior. The results in Figure 1 showed that the interaction effect of proactivity and positive feedback was significant $(\beta=0.3422, \mathrm{SE}=0.0651,95 \% \mathrm{CI}[0.2140$, $0.4705]$ ), but the interaction effect of proactivity and negative feedback was not significant ( $\beta=$ $0.3422, \mathrm{SE}=0.0651,95 \% \mathrm{CI}[0.2140,0.4705])$. Thus, task feedback moderated the relationship between proactivity and feedback-seeking behavior such that the relationship is stronger when the task feedback is positive than when the task feedback is negative. Therefore, our data supported Hypothesis 2.

Hypothesis 3 posited that the indirect effect of proactivity and creativity through feedbackseeking behavior was moderated by task feedback (positive and negative). The results showed 
that the indirect effect of proactivity and creativity when positive feedback included was not significant $(\beta=-0.0189, \mathrm{SE}=0.0122,95 \%$ CI $[-0.0470,0.0001])$. The indirect effect of proactivity and creativity when negative feedback included was also not significant ( $\beta=$ $0.0128, \mathrm{SE}=0.0114,95 \%$ CI $[-0.0055,0.0391])$. Therefore, our data did not support Hypothesis 3.

\section{Discussion}

The aim of this study is to investigate the underlying mechanisms in the relationship between proactivity and creativity. Specifically, we aim to investigate the mediating effect of feedbackseeking behavior in the proactivity-creativity relationship and the moderating effect of task feedback in the proactivity-feedback-seeking behavior relationship. Our results show that feedback-seeking behavior played a role as a mediator in the proactivity-creativity relationship, and positive feedback moderated the relationship between proactivity and creativity. Our results have been supported by the literature, for example, Kim and Wang (2008) found a positive relationship between proactivity and feedback-seeking behavior. Researchers also found that feedback-seeking behavior correlated with creativity (De Stobbeleir et al., 2011). In this study, we found that the relationship between proactivity and feedback-seeking behavior is moderated by positive task feedback, and not negative task feedback. The literature also found that positive feedback increased the effect of proactivity on feedback-seeking behavior (Anseel et al., 2015).

The indirect effect of proactivity and creativity through feedback-seeking behavior that moderated by task feedback (positive or negative), as we proposed, is not significant. By contrast with our expectation, we observe a negative relationship between feedback-seeking behavior and creativity. The negative relationship and bias are from the data because the data are collected from various industries, making the data more heterogenic regarding how industry organization could play a role in this insignificancy. However, this study could open possibilities for further investigations by adding another variable or increasing the number in the sample, because our study had a limited explanation for this special case's causality.

Our result also differs from a study that showed a positive relationship between feedbackseeking behavior and creativity (De Stobbeleir et al., 2011). We propose some plausible explanations for the unexpected result. First, other variables may moderate or mediate the relationship between feedback-seeking behavior and creativity. For example, Nae, Moon, and Choi (2015) found that perceived quality feedback and trust in supervisors mediated the relationship between feedback-seeking behavior and creativity. Third, supervisors may consider colleagues' feedback-seeking behaviors as characteristics of insecure, incompetent, attentionseeking employees; thus, employees, in this case, would be rated as low in creativity (Ashford $\&$ Northcraft, 1992; Lam, Huang, \& Snape, 2007). Fourth, the content of the feedback and the supervisor style while delivering feedback may influence employee creativity (Kim \& Wang, 2008; Oldham \& Cummings, 1996). 


\section{Theoretical Implication}

This research has several contributions to creativity literature. First, we identified feedbackseeking behavior, such as the mediator on the relationship between proactive personality and employee creativity. By examining the mediating and moderating effects, we also contribute to the literature by uncovering the underlying psychological processes on the proactive personality-creativity relationship, namely, feedback-seeking behavior, by referring to COR theory. Second, we also identified task feedback (i.e., positive and negative) as a moderator in the relationship between proactivity and creativity by referring to JCM theory. Third, we also attempted to initiate integration between individual and contextual factors of creativity that recent research has encouraged by offering feedback-related variables (feedback-seeking behavior and negative task feedback) as important psychological mechanisms that influence the relationship between proactivity and creativity.

\section{Practical Implication}

The results of this study could help managers or organizations create supportive environments for employees to enhance creativity by noticing the use of feedback because different task feedback may result in different levels of employee intrinsic motivation while improving their creativity. Managers or organizations could also encourage the use of feedback in the company and pay special attention regarding how to deliver feedback to employees.

\section{Limitation and Future Direction}

This study has several limitations. First, we use a cross-sectional method with a survey questionnaire to collect data; thus, this method may limit our ability to determine the causal relationship between our study variables. For further research, we suggest considering a longitudinal study to investigate the variance of the variables across time. Further research may also employ temporal separation by collecting the predictor, mediator, and outcome variables separately. Second, we collected the data from various companies and industries. Data from different organizational cultures may affect our results because creativity may be affected by cultures. We further suggest that researchers replicate our study but limit their data collection to only one industry to assess if our results are generalizable. Third, we analyzed only the impact of the variables on the individual level; thus, we suggest using a multilevel research design to investigate the factors that affect the relationship between proactivity and creativity at different levels.

\section{Conclusion}

This study contributes to the literature by demonstrating the mediating effect of feedbackseeking behavior on the proactivity-creativity relationship and the moderating effect of positive feedback on the relationship between proactivity and feedback-seeking behavior. Our study is also one of the first to employ the conservation of resource theory and the job characteristics model to explain our research model. 


\section{References}

Amabile, T. M. (1988). A model of creativity and innovations in organizations. Research in Organizational Behavior, 10 ,123-167.

Anseel, F., Beatty, A. S., Shen, W., Lievens, F., \& Sackett, P. R. (2015). How are we doing after 30 years? A meta-analytic review of the antecedents and outcomes of feedback-seeking behavior," Journal of Management, 41, 318-348. doi: 10.1177/0149206313 484521.

Ashford, S. J., \& Northcraft, G. B. (1992). Conveying more (or less) than we realize: the role of impressionmanagement in feedback seeking. Organizational Behavior and Human Decision Processes, 53, 310 334. doi: 10.1016/0749-5978(92)90068-I.

Baker, A., Perreault, D., Reid, A., \& Blanchard, C. M. (2013). Feedback and organizations: feedback is good, feedback-friendly culture is better. Canadian Psychology, 54, 260-268. doi: 10.1037/ a0034691.

Bateman, T. S., \& Crant, J. M. (1993). The proactive component of organizational behavior: A measure and correlates. Journal of Organizational Behavior, 14, 103-118.

Bateman, T. S., \& Crant, J. M. (1999). Proactive behavior: Meaning, impact, recommendations. Business Horizons, 42, 63-70.

Beaton, D. E., Bombardier, C., Guillemin, F., \& Ferraz, M. B. (2000). Guidelines for the process of cross-cultural adaptation of self report measures. SPINE, 25, 3186-3191. doi: 10.1097/00007632-200012150-00014.

Borden, N. H. (1984). The concept of marketing mix. Journal of Advertising Research Classics, 2, 1-12.

Chang, J. H., \& Teng, C. C. (2017). Intrinsic or extrinsic motivations for hospitality employees' creativity: The moderating role of organization-level regulatory focus. International Journal of Hospitality Management, 60, 133-141. doi: 10.1016/j.ijhm.2016. 10.003.

Costa, S. D., Paez, D., Sanchez, F., Garaigordobil, M., \& Gondim, S. (2015). Personal factors of creativity: A second order meta-analysis. Journal of work and organizational psychology, 31, 165-173. doi:10.1016/j.rpto.2015.06.002.

Crant, J. M. (2000). Proactive behaviors in organizations. Journal of Management, 26, 435-462.

De Stobbeleir, K. E., Ashford, S. J., \& Buyens, D. (2011). Self-regulation of creativity at work: the role of feedback-seeking behavior in creative performance. Academy of Management Journal, 54, 811-831.

Fedor, D. B., Rensvold, R. B., \& Adams, S. M. (1992). An investigation of factors expected to affect feedback seeking: a longitudinal field study. Personnel Psychology, 45, 779-805.

George, J. M., \& Zhou, J. (2001). When openness to experience and conscientiousness are related to creative behavior: an interactional approach. Journal of Applied Psychology, 86, 513-524. doi: 10.1037/ 00219010.86.3.513.

Gong, Y., Cheung, S. Y., Wang, M., \& Huang, J. C. (2012). Unfolding the proactive process for creativity: Integration of the employee proactivity, information exchange, and psychological safety perspectives. Journal of Management, 38, 1611-1633. doi: 10.1177/0149206310380250.

Gong, Y., Huang, J. C., \& Farh, J. L. (2009). Employee learning orientation, transformational leadership, and employee creativity: The mediating role of employee creative self-efficacy. Academy of Management Journal, 52, 765-778. doi: 10.5465/AMJ.2009.43670890

Hackman, J. R., \& Oldham, G. R. (1976). Motivation through the design of work: test of a theory. Organizational Behavior and Human Performance, 16, 250-79.

Hassan, M. U., Malik, A. A., Hasnain, A., Faiz, M. F., \& Abbas, J. (2013). Measuring employee creativity and its impact on organization innovation capability and performance in the banking sector of Pakistan. World Applied Sciences Journal, 24, 949-959. doi: 10.5829/idosi.wasj.2013.24.07.13253.

Hobfoll, S. E. (1989). Conservation of resources: a new attempt at conceptualizing stress. American Psychologist, 44(3), 513-24.

Hon, A. H. Y., Chan, W. W. H., \& Lu, L. (2013). Overcoming work-related stress and promoting employee creativity in hotel industry: The role of task feedback from supervisor, International Journal of Hospitality Management, 33, 416-424. doi: 10.1016/j.ijhm.2012. 11.001.

Hu, L., \& Bentler, P. M. (1999). Cutoff criteria for fit indexes in covariance structure analysis: conventional criteria versus new alternatives. Structural equation and modeling: A multidisciplinary journal, 6(1), 155. doi: 10.1080/10705519909540118. 
Ilgen, D. R., Fisher, C. D., and Taylor, M. S. (1979). Consequences of individual feedback on behavior in organizations. Journal of Applied Psychology, 64, 349-371.

Ito, J. K., \& Brotheridge, C. M. (2003). Resources, coping strategies, and emotional exhaustion: A conservation of resources perspective. Journal of Vocational Behavior, 63(3), 490-509. doi:10.1016/S00018791(02)00033-7.

Jain, R., \& Jain, C. (2017). Employee Creativity: A conceptual framework. Management and Labour Studies, 41, 294-313. doi: 10.1177/0258042X16676664.

Jiang, W., \& Gu, Q. (2015). A moderated mediation examination of proactive personality on employee creativity: A person-environment fit perspective. Journal of Organizational Change Management, 28, 393-410. doi: 10.1108/JOCM-05-2014-0088.

Kim, T. Y., Hon, A. H. Y., \& Lee, D. R. (2010). Proactive personality and employee creativity: the effects of job creativity requirement and supervisor support for creativity. Creativity Research Journal, 22, 37-45. doi: 10.1080/10400410903579536.

Kim, T. Y, Hon, A. H. Y., \& Crant, J. M. (2009). Proactive personality, employee creativity, and newcomer outcomes: A longitudinal study. Journal of Business and Psychology, 24, 93-103, doi: 10.1007/s 10869009-9094-4.

Kim, T. Y., \& Wang, J. (2008). Proactive personality and newcomer feedback seeking: The moderating roles of supervisor feedback and organizational justice. Current Topics in Management, 13, 91-108.

Lam, W., Huang, X., \& Snape, E. (2007). Feedback seeking behavior and Leader Member Exchange: Do supervisor attributions matter. Academy of Management Journal, 50, 348-363. doi: 10.5465/AMJ.2007.24634440.

Li, X., \& Qian, J. (2016). Stimulating employees' feedback-seeking behavior: the role of participative decision making. Social Behavior and Personality, 44, 1-8. doi:10.2224/sbp.2016.44.1.1

Nae, E. Y., Moon, H. K., \& Choi, B. K. (2015). Seeking feedback but unable to improve work performance? Qualified feedback from trusted supervisors matters. Career Development International, 20, 81-100. doi: 10.1108/CDI-08-2014-0107.

Oldham, G. R., \& Cummings, A. (1996). Employee creativity: Personal and contextual factors at work. Academy of Management Journal, 39, 607-634.

Seibert, S. E., Crant, J. M., \& Kraimer, M. L. (1999). Proactive personality and career success. Journal of Applied Psychology, 84, 416-427.

Shalley, C. E., Zhou, J., \& Oldham, G. R. (2004). The effects of personal and contextual characteristics on creativity: Where should we go from here?. Journal of Management, 30, 933-958. doi: 10. 1016/j.jm. 2004.06.007

Tierney, P., Farmer, S. M., \& Graen, G. B. (1999). An examination of leadership and employee creativity: The relevance of traits and relationships. Personnel Psychology, 52, 591-620.

Wu, C. H., Parker, S. K., \& De Jong, J. P. J. (2014). Feedback seeking from peers: a positive strategy for insecurely attached team workers. Human Relations, 67(4), 441-464. doi: 10.1177/ 0018726713496124.

Zhou, J. (1998). Feedback valence, feedback style, task autonomy, and achievement orientation: Interactive effects on creative performance. Journal of Applied Psychology, 83(2), 261-276. doi: 10.1037/00219010.83.2.261. 